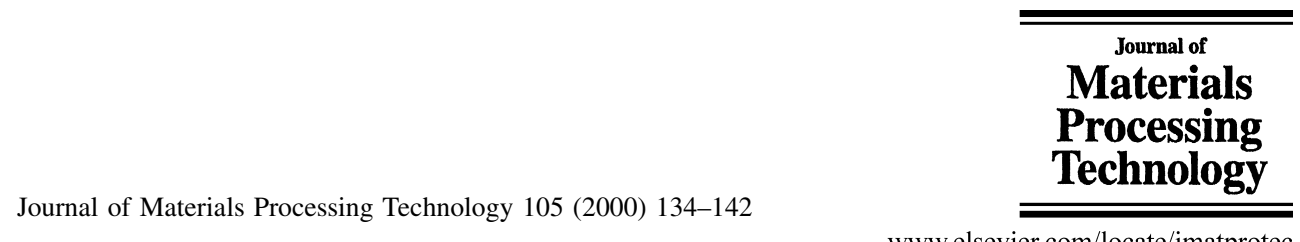

www.elsevier.com/locate/jmatprotec

\title{
Failure analysis of a cold-extrusion punch to enhance its quality and prolong its life
}

\author{
Yi-Che Lee, Fuh-Kuo Chen* \\ Department of Mechanical Engineering, National Taiwan University, No. 1 Roosevelt Road, Sect. 4, Taipei 10764, Taiwan, ROC
}

Received 4 June 1999

\begin{abstract}
A cold-extrusion punch used to manufacture sockets undergoes severe impact loading and severe wear in the metal forming process. Failure in the cold-extrusion punch frequently occurs and is difficult to avoid. Owing to the complicated manufacturing process and the lack of service history of the cold-extrusion punch, detecting the major causes of the punch failure is difficult. Therefore, this study analyzes the major causes of the failure of a cold-extrusion punch by initially examining the mechanical properties of the cold-extrusion punch to identify defects in its related performance. Eliminating such defects is necessary to enhance the quality of the cold-extrusion punch. To determine the major causes of failure of the cold-extrusion punch, the characteristics of the failure are compared with those of well-known failure mechanisms, including the macro- and micro-characteristics of failure mechanisms. By closely examining the results of the mechanical properties and the results of the failure analysis of a cold-extrusion punch, this study proposes an effective method to avoid punch failure and prolong the punch life. (C) 2000 Elsevier Science S.A. All rights reserved.
\end{abstract}

Keywords: Cold-extrusion punch; Failure analysis; Punch life

\section{Introduction}

The tools used in the metal forming process generally consist of a die and a punch. Compiling a complete manufacturing process and service history of the tools used in metal forming processes is a rather complicated task. Many process parameters contribute to tool failure. Owing to the diverse service conditions under which tools are applied, identifying the major causes of tool failure is extremely difficult. The common causes of tool failure include the deformation history, wear, thermal fatigue and mechanical fatigue.

Therefore, the major causes of tool failure must be identified to prevent such failure and to ensure an acceptable tool life. To find the major causes of tool failure, a simultaneous investigation should be made of the service conditions of the tool and both the macro- and micro-characteristics of the failure mechanism are identified. In the failure analysis process, various characteristics of the service conditions for each tool must be outlined to narrow down the area of focus and to identify causes of failure. Moreover, the macro- and

\footnotetext{
* Corresponding author. Tel.: +886-2-2366-1322; fax: +886-2-2363-1755.

E-mail address: fkchen@w3.me.ntu.edu.tw (F.-K. Chen).
}

micro-characteristics of tool failure should be compared with those of well-known factors contributing to failure that are identified by considering the service conditions of the tool. Such a comparison would allow the determination of the major causes of tool failure.

This study investigates a punch used in the cold-extrusion process to manufacture sockets, as illustrated in Fig. 1. In the cold-extrusion process, the punch must undergo severe impact loading and severe wear. Due to the service conditions of the cold-extrusion punch, the common causes of failure are plastic deformation, mechanical fatigue and wear, resulting in the gradual deterioration of the performance of the punch. Therefore, the cold-extrusion punch must be made using materials having a high hardness and toughness. Furthermore, some surface treatments that coat hard surface layers onto the matrix material are applied for protecting the matrix from wear damage.

The cold-extrusion punch investigated in this study is made of high strength steel coated with $\mathrm{TiC}$ and $\mathrm{TiN}$ by the chemical vapor deposition method (CVD) and hardened by appropriate heat treatment. To investigate the causes of punch failure, the mechanical properties of the punch are initially examined to discover the defects associated with the punch performance. Next, the characteristics of the punch failure are compared with those of well-known failure 

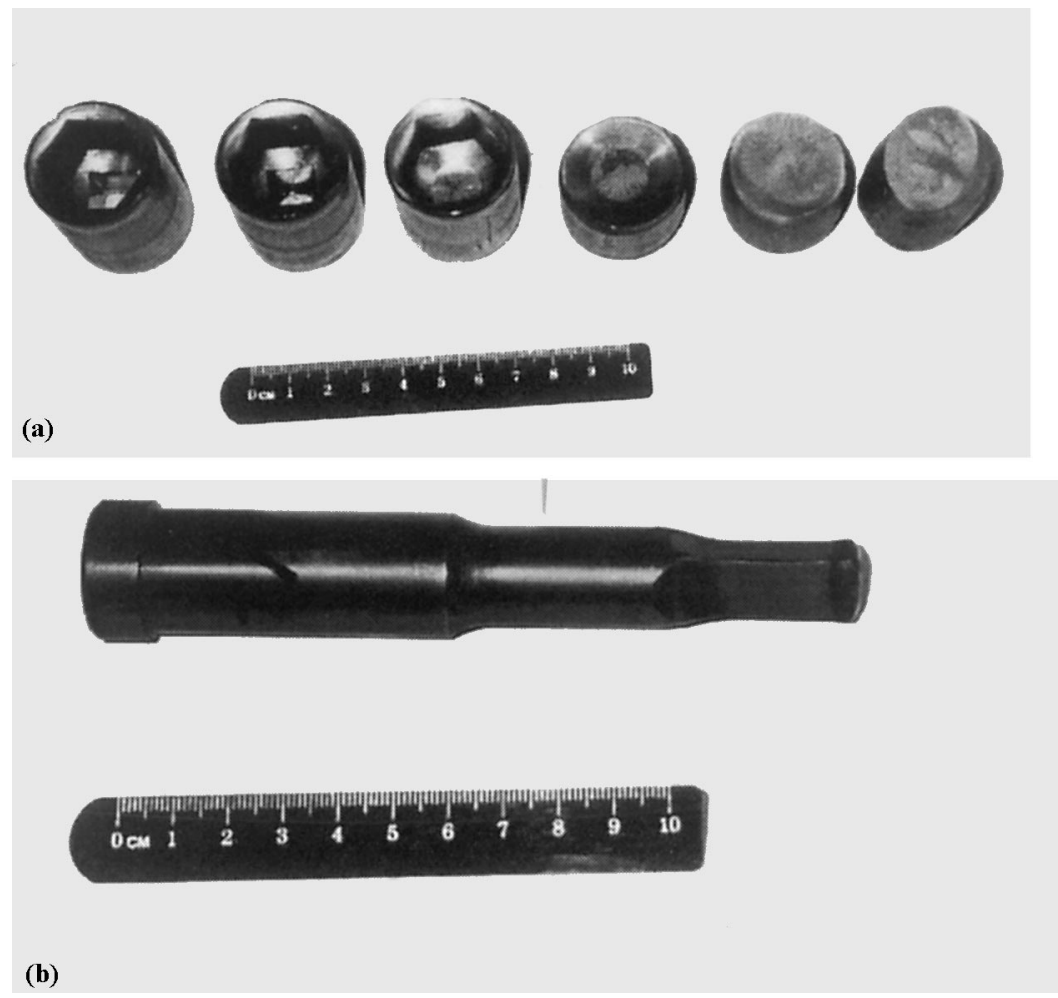

Fig. 1. (a) The forming process of the socket. (b) The cold-extrusion punch used for the manufacturing of the socket.

mechanisms, including the macro- and micro-characteristics of failure mechanisms to determine the major failure mechanism of the cold-extrusion punch. Furthermore, the service conditions and major failure mechanisms of the cold-extrusion punch are investigated simultaneously to identify the major causes of the punch failure. While considering the defects associated with the punch performance and the major causes of punch failure, this study also proposes a method to enhance the punch quality and prolong the punch life.

\section{Mechanical properties of the cold-extrusion punch}

The mechanical properties of the cold-extrusion punch, e.g., the chemical composition, surface treatment and microstructure, were initially examined to identify the defects associated with the punch performance. The defects can be viewed as contributing to tool failure so that a method can be proposed to enhance the punch performance. The procedures and results of the investigation of the mechanical properties of the cold-extrusion punch are summarized as follows.

\subsection{Chemical composition}

The cold-extrusion punch used in this study is made of a high-strength steel. The high strength steel contains mainly $1.3 \% \mathrm{C}, 10.5 \% \mathrm{Mo}, 6.25 \% \mathrm{~W}, 3.75 \% \mathrm{Cr}$ and the balance $\mathrm{Fe}$, which resembles common high-speed steel. Table 1 lists the chemical compositions of the high strength steel, which was donated by a materials supply company. Although the highstrength steel contains higher contents of elements $\mathrm{C}$ and Mo than those of common high speed steel, the high strength steel contains only a slight amount of the element Co. High contents of elements $\mathrm{C}$ and Mo in high-strength steel can increase the resistance to wear. However, high contents of the element Co may reduce the material toughness. On the

Table 1

The compositions of common die materials

\begin{tabular}{|c|c|c|c|c|c|c|c|c|c|c|}
\hline$\%$ & $\mathrm{C}$ & $\mathrm{Mn}$ & $\mathrm{Si}$ & $\mathrm{Cr}$ & $\mathrm{Ni}$ & Mo & $\mathrm{W}$ & $\mathrm{V}$ & Co & $\mathrm{S}$ \\
\hline The punch material & 1.3 & 0.35 & 0.35 & 3.75 & - & 10.50 & 6.25 & 2.00 & - & 0.07 \\
\hline M35 (SKH55) & $0.82-0.88$ & $0.15-0.40$ & $0.20-0.45$ & $3.75-4.50$ & 0.30 max. & $4.50-5.50$ & $5.50-6.70$ & $1.75-2.20$ & $4.50-5.50$ & - \\
\hline M41 (SKH55) & $1.05-1.15$ & $0.20-0.60$ & $0.15-0.50$ & $3.75-4.50$ & 0.30 max. & $3.25-4.25$ & $6.25-7.00$ & $1.75-2.25$ & $4.75-5.75$ & - \\
\hline M2 (SKH9) & $0.75-0.88$ & $0.15-0.40$ & $0.20-0.45$ & $3.75-4.50$ & 0.30 max. & $4.50-5.50$ & $5.50-6.75$ & $1.75-2.20$ & - & - \\
\hline
\end{tabular}




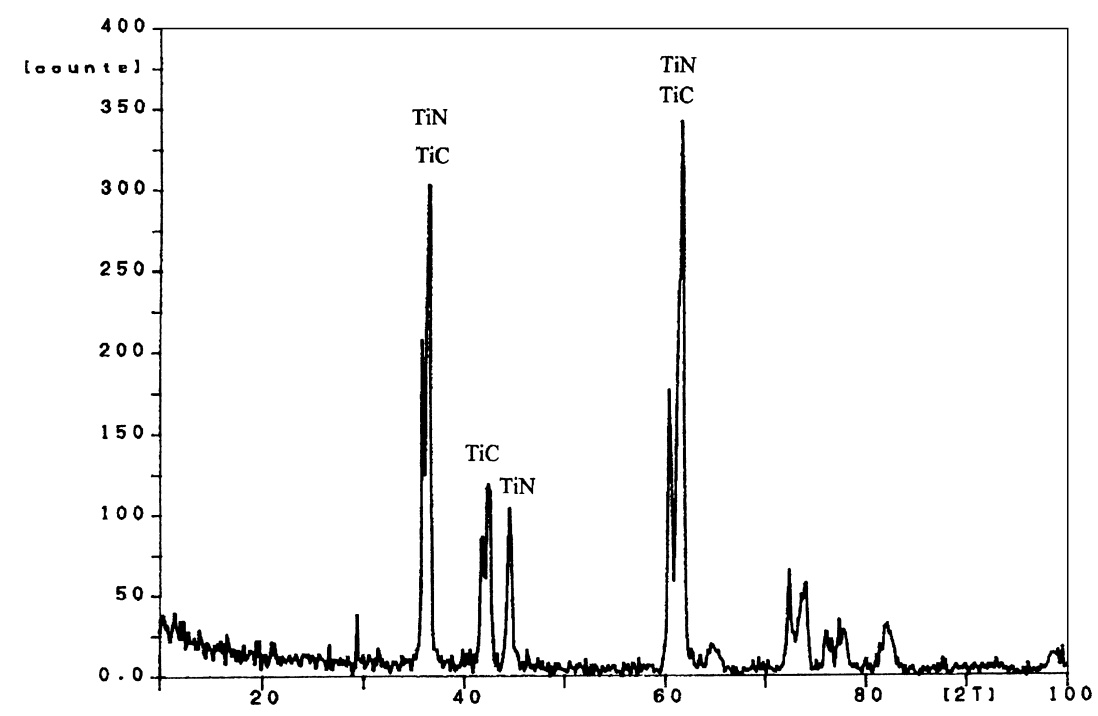

Fig. 2. The XRD results for the surface layer.

other hand, the content of element $\mathrm{C}$ in the high-strength steel is higher than that in common high-speed steels which may yield coarse carbides under conditions of high temperature in the processes of surface treatment and heat treatment.

\subsection{Surface treatment}

The surface properties of a punch can generally be enhanced by surface treatments which coat harder compounds (e.g., TiC, $\mathrm{TiN}, \mathrm{TiCN}$, and $\mathrm{TaC}$ ) on the material surface by a single layer or several layers. Due to the uniform diffusion zone between the subsurface layer and the surface layer, the excellent surface layer is barely peeled off the matrix material of the punch. The hardness of the surface layer normally ranges from around Hv 2300-3800 (micro-Vickers hardness: Hv). In addition, the quality of the surface layer can be maintained under the service conditions of temperatures exceeding $500^{\circ} \mathrm{C}$.

The compounds used, thickness and hardness of the surface layer are factors contributing to the mechanical properties of the surface layer. In this study, we analyze the surface layer of the cold-extrusion punch by X-ray diffractometer (XRD) to identify the compounds of the surface layer. According to XRD results in Fig. 2, the surface layer contains the compounds $\mathrm{TiC}$ and TiN. Furthermore, this study also analyzes the element distributions and the thickness of the surface layer by electro probe microanalyzer (EPMA), as depicted in Fig. 3. The elements of Ti, C and $\mathrm{N}$ are largely contained and are uniformly distributed on the surface layer. The surface layer is a single layer that contains the uniform mixed compounds of TiC and TiN. The thickness of the surface layer is about $5 \mu \mathrm{m}$. On the other hand, the hardness of the surface layer examined by micro-Vickers hardness testing is about $2600 \mathrm{Hv}$, i.e., sufficiently high for the cold-extrusion punch. Summing up the CVD and EPMA results, the material surface contains a uniform distribution layer of TiC and TiN. Moreover, the thickness and hardness of the surface layer are also in the range of proper design.

The material of the surface layer must harmonize with the matrix material to prevent easy peeling of the surface layer from the matrix material of the punch. A situation in which the mechanical properties of the surface layer obviously differ from those of the matrix material can induce discontinuous mechanical properties between the surface layer and the matrix material of the cold-extrusion punch [1]. Under this circumstance, the surface layer of the cold-extrusion punch easily peels from the matrix material. Table 2 lists the mechanical properties of the surface layer and the matrix material of the cold-extrusion punch. The material properties that profoundly affect the harmonization of those

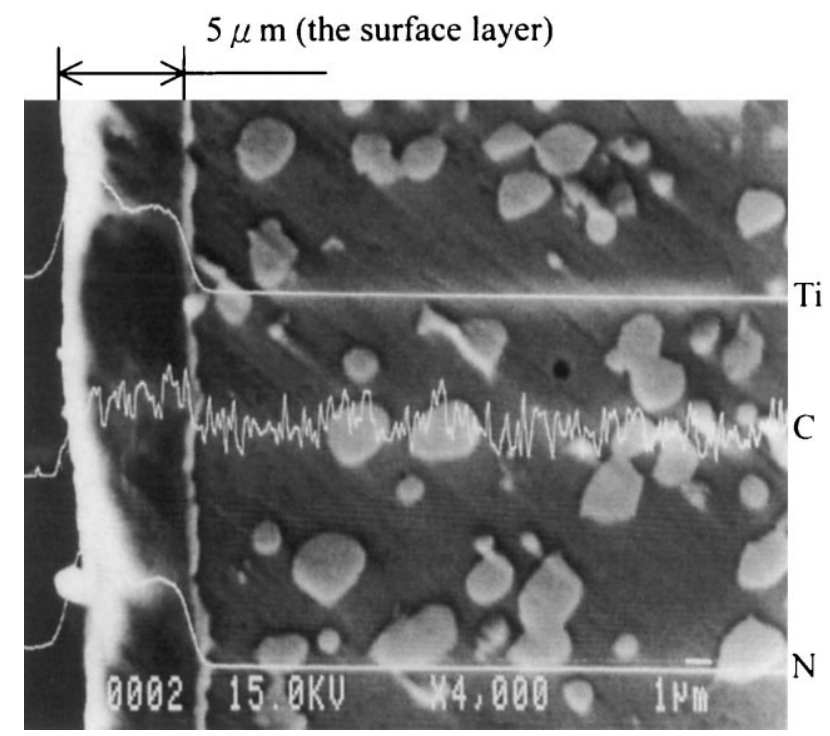

Fig. 3. The EPMA results for the surface layer. 
Table 2

The mechanical properties of the surface layer and the punch material

\begin{tabular}{|c|c|c|c|}
\hline Material & Young's modulus, $E(\mathrm{GPa})$ & Thermal expansion coefficient, $\alpha\left({ }^{\circ} \mathrm{C}\right)$ & $E \alpha\left(\mathrm{GPa} /{ }^{\circ} \mathrm{C}\right)$ \\
\hline $\mathrm{TiC}$ & 350 & $7 \times 10 \mathrm{E}-6$ & $2.45 \times 10 \mathrm{E}-6$ \\
\hline The punch material & 245 & $12 \times 10 \mathrm{E}-6$ & $2.94 \times 10 \mathrm{E}-6$ \\
\hline
\end{tabular}

materials are Young's modulus $(E)$ and the coefficient of thermal expansion $(\alpha)$ of the punch material. As generally assumed, the value of the product of $E$ and $\alpha$ is an important determinant as to whether or not the materials are harmonic with each other [2]. In this study, the value $E \alpha$ of the surface layer and the matrix material of the cold-extrusion punch are close to each other. Therefore, the compounds of the surface layer, TiN and $\mathrm{TiC}$, harmonize with the matrix material of the cold-extrusion punch. Moreover, the quality of the surface layer of the cold-extrusion punch is excellent.

\subsection{Microstructure}

During the surface treatment of the cold-extrusion punch, the temperature ranges from about 900 to $1200^{\circ} \mathrm{C}$. The microstructure of the punch material can be transformed to austenite by the high temperature of the surface treatment. If the cooling rate is low in a high temperature condition, the microstructure of the punch material is transformed from $\alpha$-iron to pearlite (ferrite+cementite or $\varepsilon$-carbide). Following the surface treatment, the cold-extrusion punch is hardened by heat treatment. During the heat treatment, the quenching temperature ranges from about 1200 to $1300^{\circ} \mathrm{C}$ and the tempering temperature extends from about 500 to $600^{\circ} \mathrm{C}$. Following the heat treatment, the microstructure of the punch material is transformed mainly into temper martensite. Simultaneously, the carbides of the punch material gradually grow due to the high temperature conditions and the long heating period of tempering treatment.

To examine the microstructure of the punch material, this study analyzes the metallographic structures of the punch material for different treatment processes, including the surface treatment and the heat treatment, by metallography testing, as displayed in Fig. 4 which reveals that the microstructure of the punch material is transformed from pearlite to temper martensite and that the fine carbides of the punch material gradually become coarser carbides. On the other hand, Fig. 5 indicates that the grain size of the punch material is approximately $50 \mu \mathrm{m}$ (ASTM grain number: 5-6) after the surface treatment and the heat treatment. The grain growth becomes obvious during the heat treatment.

Table 3 summarizes the above results, including those for the hardness of the surface layer and the matrix material, the thickness and composition of the surface layer and the microstructure of the punch material. Regarding the results obtained from surface treatment, the thickness, hardness and compounds of the surface layer are standard requirements; the quality of the surface layer is also excellent. Comparison of the results before and after heat treatment reveals that they do not significantly differ. In addition, the hardness of the

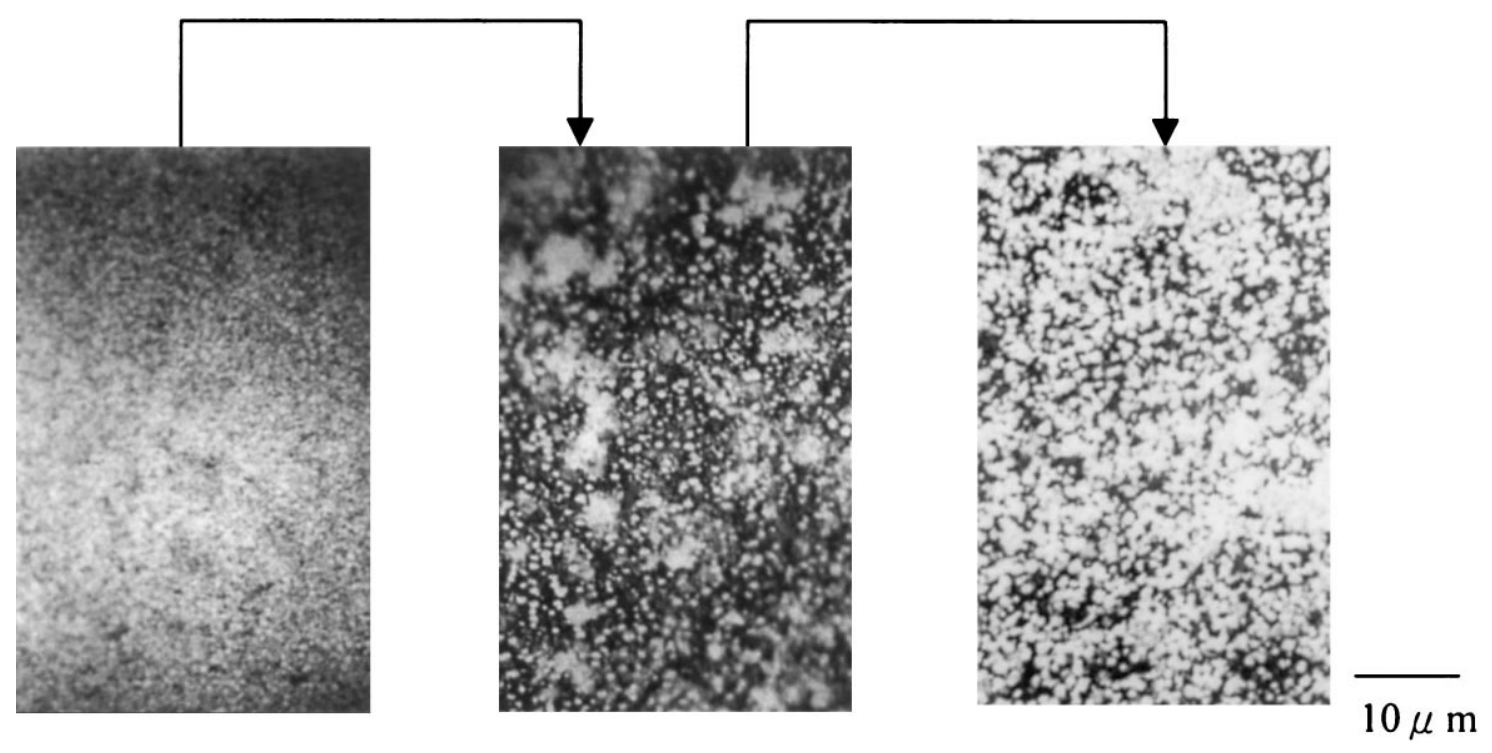

Fig. 4. The microstructure change of the punch material. 


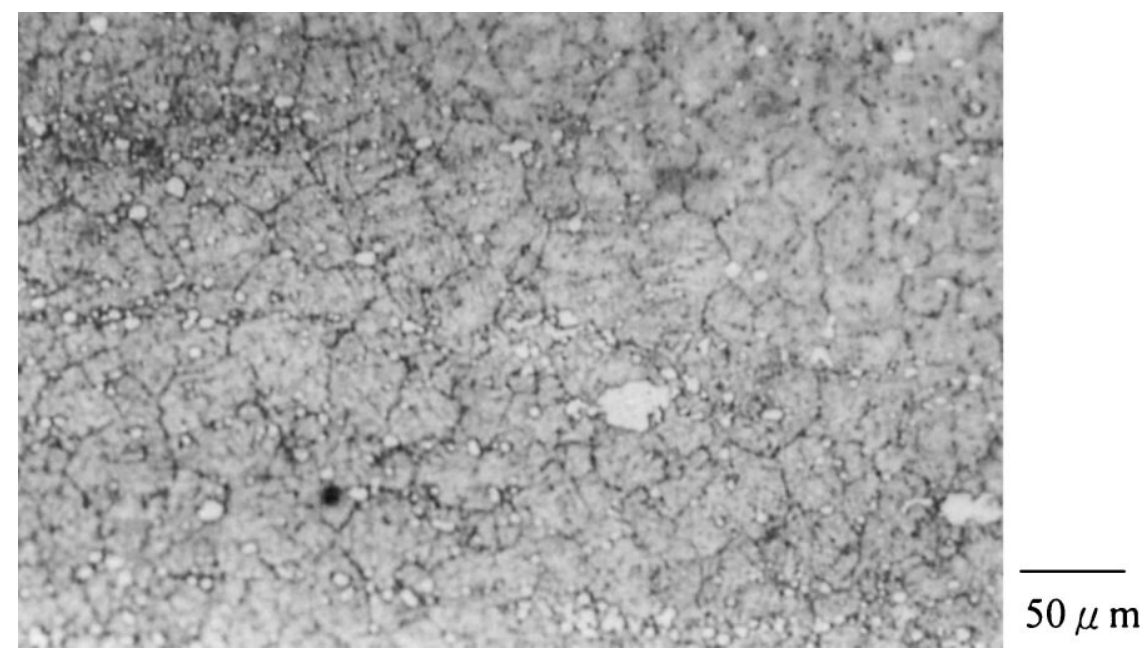

Fig. 5. The grain size of the punch material after heat treatment.

punch material is sufficient after heat treatment, as indicated in Table 3. Following heat treatment, the carbide size is coarser than before. Interestingly, coarser carbides in the punch material may reduce the resistance to wear and the fatigue strength of the punch material.

Close examination of the results obtained from mechanical properties of the cold-extrusion punch reveals that grain growth and coarser carbide are the major defects of the punch performance, which provide a criteria for upgrading the punch quality. Notably, too high a temperature and too long a heating period in the surface treatment and the heat treatment largely contribute to grain growth and coarser carbide. Therefore, carefully controlling the temperature and heating period significantly contribute to the performance of the cold-extrusion punch.

\section{Causes for failure of the cold-extrusion punch}

During the extrusion process, the surface layer and the matrix material of the cold-extrusion punch endure different service environments. The surface layer typically suffers from wear damage and high temperatures because the forming material flows quickly between the forming material and the surface layer during the material forming process. The fact that the surface layer resists surface damage to the matrix material explains why the matrix material mainly suffers from impact loading during the material forming process.

To identify the major causes of punch failure, this study simultaneously investigates the macro- and micro-characteristics of the punch failure to elucidate the punch failure mechanism. The service conditions and the stress concentration locations of the punch are also considered simultaneously for elucidating the macro-characteristics of the punch failure. On the other hand, scanning electron microscope (SEM) was performed to analyze the micro-characteristics of the punch failure. The causes of punch failure can be identified by comparing its macro- and micro-characteristics with those of a well-known failure mechanism, such as fatigue or wear.

Figs. 6 and 7 reveal that fracture occurs at the sharp corner of the punch top, resulting in punch failure. According to Fig. 6, a crack begins in the neighborhood of the contact surface of the punch top. Moreover, the crack may gradually spread to the punch interior until the sharp corner is finally peeled away from the punch top, as shown in Fig. 7. To investigate the initiation and growth of the crack, this study examines the failure characteristics of the surface layer and the matrix material of the cold-extrusion punch.

For the failure characteristics of the surface layer, severe wear damage always occurs on the surface of the sharp

Table 3

The examination results of the mechanical properties of the punch

\begin{tabular}{lllll}
\hline & $\begin{array}{l}\text { Hardness of the matrix } \\
\text { material }(\mathrm{HRc})\end{array}$ & $\begin{array}{l}\text { Hardness of the } \\
\text { surface layer }(\mathrm{Hv})\end{array}$ & $\begin{array}{l}\text { Thickness of the } \\
\text { surface layer }(\mu \mathrm{m})\end{array}$ & $\begin{array}{l}\text { Compounds of the } \\
\text { surface layer }\end{array}$ \\
\hline $\mathrm{A}^{\mathrm{a}}$ & 40 & $2300-3000$ & 5 & TiN+TiC \\
$\mathrm{B}^{\mathrm{b}}$ & 65 & $2800-3600$ & 5 & TiN+TiC \\
\hline
\end{tabular}

\footnotetext{
${ }^{a}$ After the surface treatment and before the heat treatment.
}

${ }^{\mathrm{b}}$ After the surface treatment and the heat treatment. 


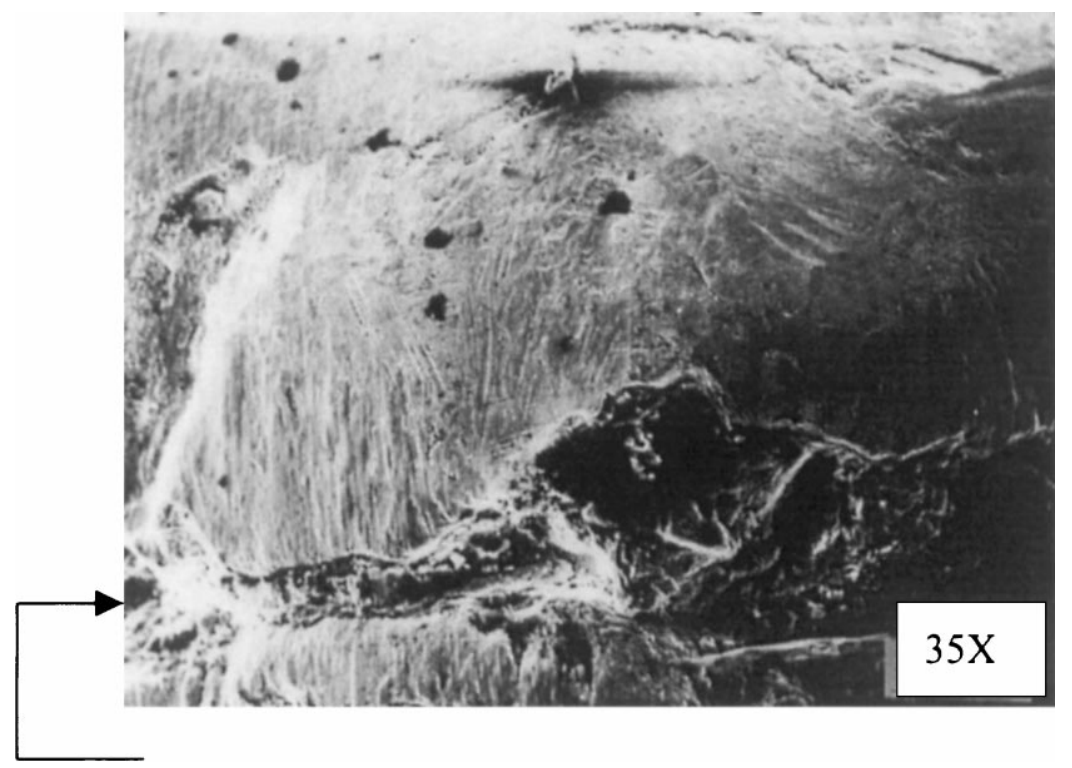

Fig. 6. The crack initiation in the neighborhood of the contact surface of the punch top.

corner of the punch top during the extrusion process. Under these circumstances, the surface layer easily peels from the matrix material. SEM and metallography tests are performed to investigate the failure characteristics of the sharp corner of the punch top. The micrograph obtained by SEM, as shown in Fig. 8, indicates that the surface layer is peeled from the matrix material and the matrix material is exposed to the service environment. From the micrograph in Fig. 9, as obtained by metallography testing, peeling becomes more obvious when examining the zone of the peeled surface layer. Therefore, the surface layer does not deteriorate gradually by wearing only, but is peeled from the matrix material. The cyclic impact loading is also a major cause for failure of the surface layer. On the other hand, when the surface layer is peeled from the matrix material, a crack occurs in the neighborhood of the contact surface of the punch top, as shown in Fig. 6. Therefore, the peeled surface layer does not significantly contribute to punch failure.

For the failure characteristics of the matrix material, a crack usually occurs in the sharp corner of the punch top. The crack grows gradually, resulting in punch fracture owing to the service conditions of cyclic impact and stress concentration. The fact that the crack grows gradually in the service

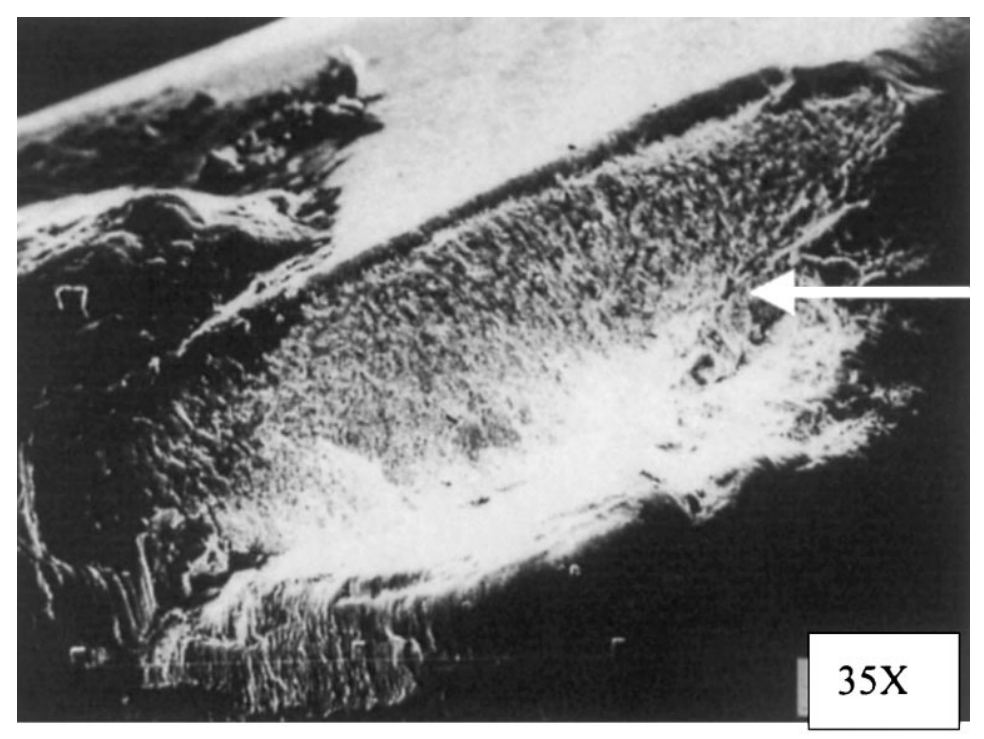

Fig. 7. The fracture zone in the sharp corner of the punch top. 


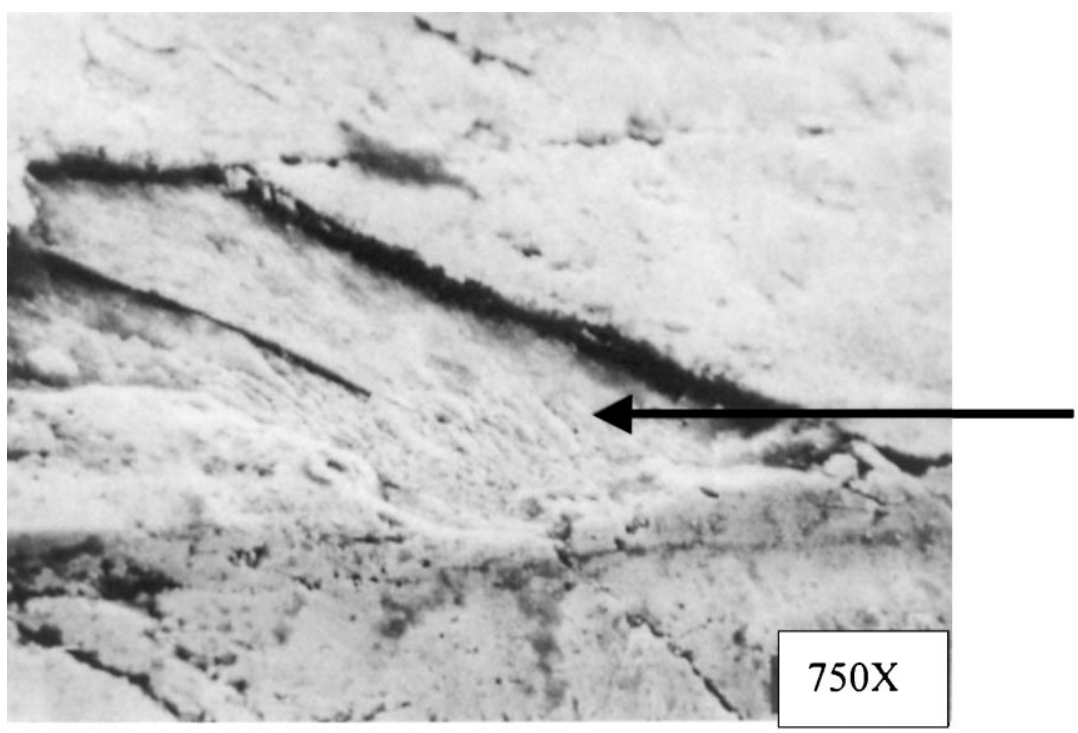

Fig. 8. The peeled zone of the surface layer.

condition of cyclic impact loading accounts for the present assumption that the mechanism of fatigue fracture is the major cause for punch failure.

Among the macro-characteristics of fatigue fracture include the location of crack initiation, the direction of crack growth, and the features of the crack surface. For the punch failure investigated herein, crack initiation usually occurs in the stress concentration which is in the neighborhood of the sharp corner of the punch top. In addition, the crack gradually grows into the interior of punch, as shown in Fig. 10(a). For the characteristics of contact fatigue fracture, a crack occurs in the sub-surface layer of the loading surface and the crack surface is usually parallel to a loading surface, as shown in Fig. 10(b). Comparing Fig. 10(a) with (b) reveals that the fracture mechanism of the punch failure corresponds to that of contact fatigue [3].
On the other hand, beach marks are prominent features of fatigue fracture. Beach marks frequently appear on the crack surfaces of fatigue. Since beach marks denote the position of crack front at a certain time interval, beach marks must encircle an origin which is usually the position of crack initiation, i.e. the "crack origin". Herein, the fracture surface of the punch failure has a crack origin and beach marks, as shown in Fig. 11. Owing to the crack originating in the neighborhood of the punch exterior, the present results demonstrate that the fatigue crack initiates in the punch exterior and grows gradually into the punch interior.

Since the cyclic extrusion process results in the cyclic open-close of a crack, the small pieces of the matrix material on the crack surface rub against each other [4]. The small pieces that rub against each other gradually become spherical particles, which are overcrowded in the

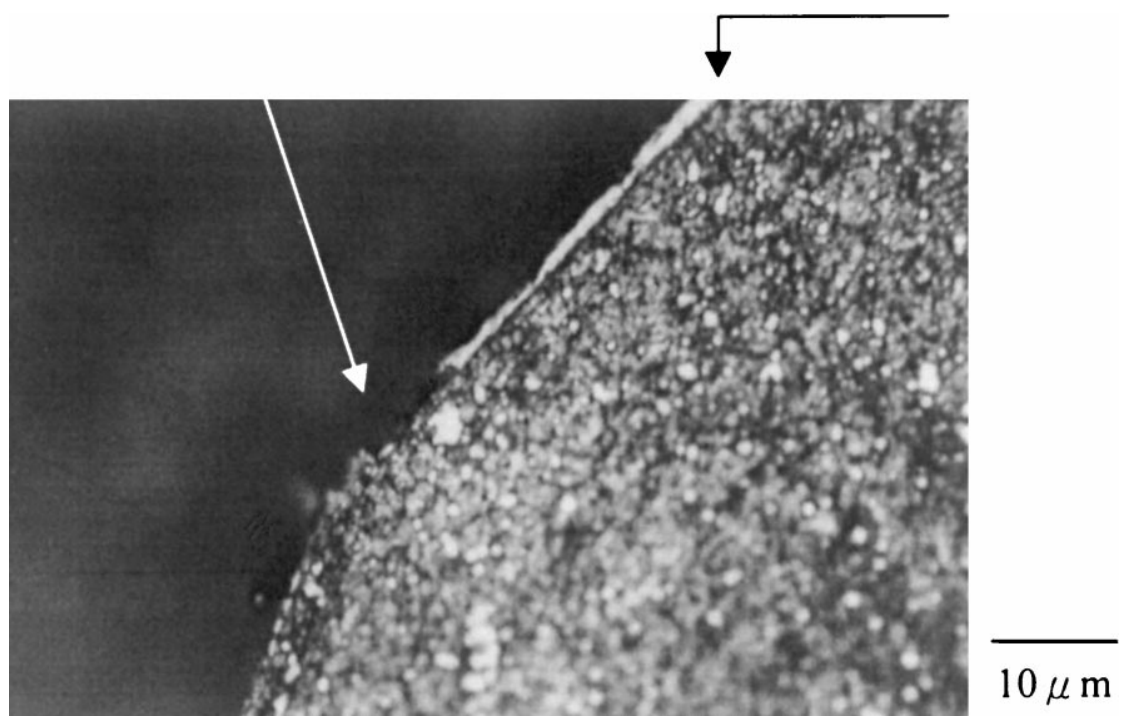

Fig. 9. The sharp corner of the punch failure. 


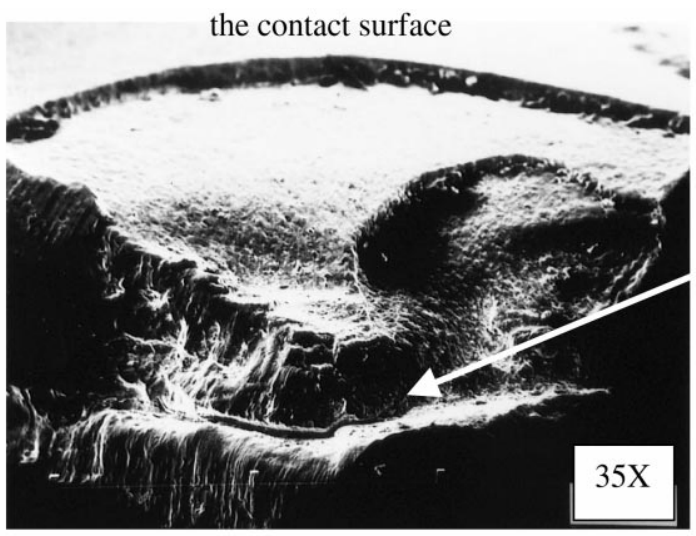

(a)

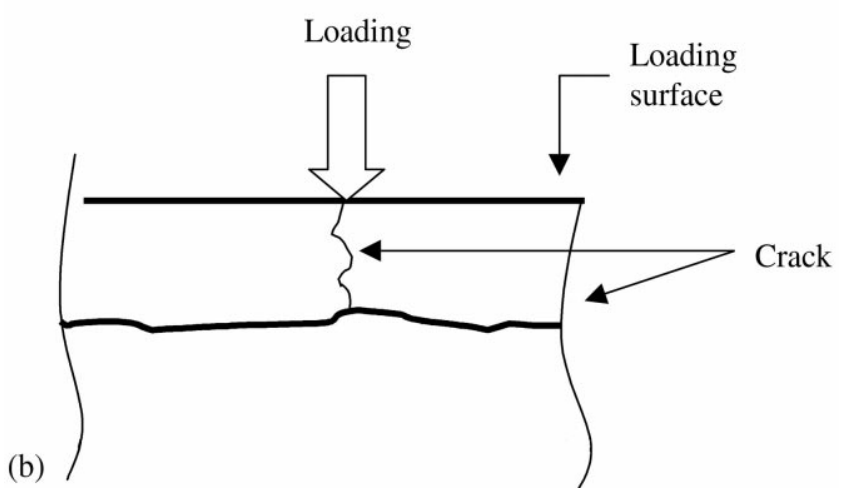

Fig. 10. (a) The characteristics of the contact fatigue fracture. (b) The crack surface is usually parallel to a loading surface.

crack opening, as shown in Fig. 12. As mentioned earlier, the major fracture mechanism of the matrix material closely resembles that of fatigue fracture.

\section{Results and discussion}

According to results obtained from the mechanical properties of the punch, the grain growth and carbide coarseness of the punch material induced by the high temperature condition are the major defects of the punch performance. Due to the cyclic impact loading in the extrusion process, fatigue fracture is the major contributing factor of the punch failure. Simultaneously, the surface layer can be peeled from the matrix material of the punch, resulting in the exposed zone of the matrix material in the sharp corner of the punch. However, the wear damage of the surface layer is not a major contributing factor of punch failure. The matrix material is exposed directly to conditions of high temperature and wear damage, thereby accelerating punch fracture.

According to previous investigations, a high temperature generally induces grain growth and carbide coarseness, ultimately reducing the strength, ductility and toughness of the punch material [5-7]. Owing to the harmful effect of the coarse grain and carbide towards the fatigue strength of the punch material, the formation and propagation of a fatigue crack cannot be presented effectively. However, a high temperature $\left(900-1200^{\circ} \mathrm{C}\right)$ for an extended period is usually necessary during surface treatment (CVD). For fine grain steels, the temperature resulting in coarse grain is about $1040^{\circ} \mathrm{C}$. If the temperature during the heat treatment exceeds $1040^{\circ} \mathrm{C}$, the compounds obstructing initial grain growth, such as $\mathrm{AlN}, \mathrm{TiC}, \mathrm{TiCN}$, in the punch material are suddenly incorporated into the matrix phase, resulting in unrestrained growth of grain. The above phenomenon is called "secondary recrystallization" or "discontinued grain growth". Therefore, controlling the temperature during the heat treatment is a prerequisite for avoiding the abnormal growth of grain.

On the other hand, a long heating period at a high temperature is also a major contributing factor of grain growth and coarse carbides. An excessively long heating period must be averted during surface treatment and heat treatment. During surface treatment, the heating period is shortened resulting in a lesser thickness of the surface layer. However, the lesser thickness of the surface layer is excellent for significantly reducing the difference between the temperature gradient and the discontinuous mechanical properties between the surface layer and the matrix material of the cold-extrusion punch. Therefore, a shortened heating
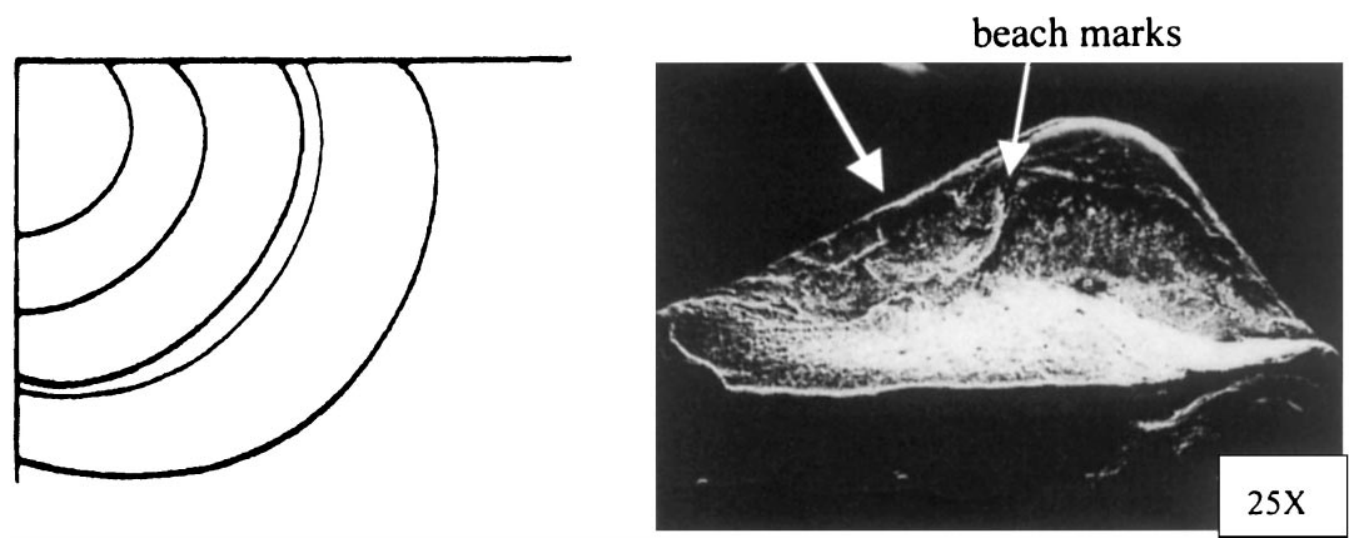

Fig. 11. The crack origin and the beach marks. 


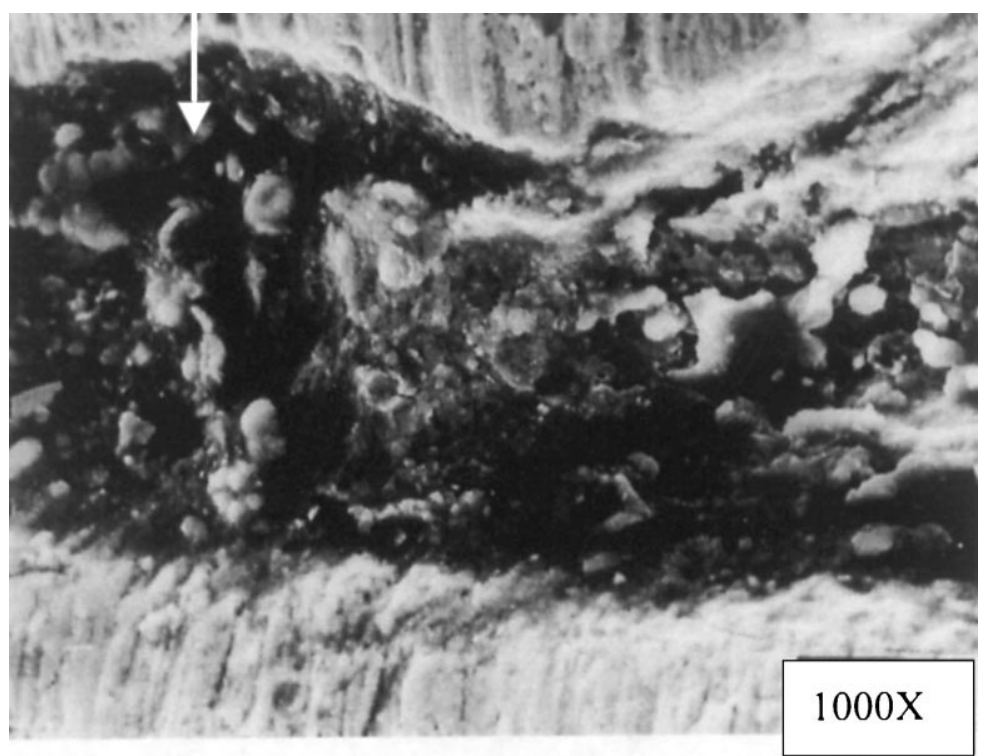

Fig. 12. The rubbed pieces of the punch material.

period of the surface treatment can simultaneously enhance the performance of the surface layer and the matrix material of the cold-extrusion punch.

During heat treatment, the microstructure of the punch material is transformed from austenite into ferrite and spherical carbides. The microstructure change is accompanied by an expansion in volume of the cold-extrusion punch, which becomes obvious in the sharp corner of the punch top. The microstructure transformation of the punch material not only induces the geometric deformation of the punch, but also abnormal stress concentration in the sharp corner of the punch top. Therefore, at the sharp corner of the punch top, fractures occur easily which reduces the usefulness of the punch.

\section{Conclusions}

A cold-extrusion punch is used both in the service conditions of impact loading and severe wear. Fatigue fracture is a major contributing factor of punch failure. Therefore, to prolong the punch life, the fatigue strength of a punch must be increased. By considering the manufacturing process of the cold-extrusion punch, this study improves the punch material with respect to the resistance of fatigue fracture and wear damage by surface treatment and heat treatment. Owing to the necessity of a high temperature and a long heating period during surface treatment and heat treatment, grain growth and coarse carbides cannot be avoided. Therefore, the material chosen for the cold-extrusion punch must contain proper elements, such as $\mathrm{Mo}, \mathrm{V}, \mathrm{Ti}, \mathrm{Mb}$, and $\mathrm{Zr}$, to prevent grain growth. A lower $\mathrm{C}$ content of the material must be selected to avoid coarse carbides from occurring. On the other hand, during surface treatment and heat treatment, the high temperature and the heating period must be properly controlled. A thinner surface layer should be selected to shorten the heating period and enhance the performance of the surface layer. If a material containing proper compounds is chosen to make a cold-extrusion punch and the heating periods of the surface treatment and the heat treatment are shortened, the punch quality can be enhanced and the punch life prolonged.

\section{References}

[1] M.D. Thouless, Some mechanics for the adhesion of thin films, Thin Solid Films 181 (1989) 397-406.

[2] M.B. Peterson, S. Ramalingam, Fundamental of friction and wear of materials, in: D.A. Rigney (Ed.), Proceedings of Materials Science Seminar, ASM, 1980, p. 366.

[3] V.J. Colangelo, F.A. Heiser, Analysis of Metallurgical Failures, Wiley, New York, 1987, p. 158.

[4] K. Saruki, S. Hotta, H. Fujita, T. Arai, Fatigue strength of steels with thin hard coating, Thin Solid Films 181 (1989) 383-395.

[5] J. Polak, Cyclic Plasticity and Low Cycle Fatigue Life of Metals, Elsevier, New York, 1991, pp. 53-56.

[6] S.Q. Wang, X.Z. Feng, S.J. Tian, The effect of microstructures on fatigue crack propagation rate of die steels, in: P.O. Kettunen, T.K. Lepisto, M.E. Lehtonem (Eds.), Proceedings of the Eighth International Conference on the Strength of Metals and Alloys, Vol. 2, 1988, pp. 805-810.

[7] A. Puskar, Microplasticity and Failure of Metallic Materials, Elsevier, New York, pp. 282-290. 